\title{
Teaching and Learning with Structured Knowledge Maps: An Analysis about the New Approach
}

\section{Nayara Silva Costa, Carlos Alberto Lopes da Silva, Daniela Carvalho Monteiro Ferreira, Luciano Vieira Lima}

Universidade Federal de Uberlândia: Electrical Engineering Faculty, COPEL, Uberlândia, Brazil

Email: vieira@ufu.br

How to cite this paper: Costa, N. S., da Silva, C. A. L., Ferreira, D. C. M., \& Lima, L. V. (2016). Teaching and Learning with Structured Knowledge Maps: An Analysis about the New Approach. Creative Education, 7, 2212-2225.

http://dx.doi.org/10.4236/ce.2016.715218

Received: August 1, 2016

Accepted: September 17, 2016

Published: September 20, 2016

Copyright $\odot 2016$ by authors and Scientific Research Publishing Inc. This work is licensed under the Creative Commons Attribution International License (CC BY 4.0).

http://creativecommons.org/licenses/by/4.0/

\begin{abstract}
The aims of this paper are to present two methods combined for teaching and learning processes based on the Categories Theory and Knowledge Maps, and to invite the academic community, in different areas of knowledge, particularly in education, to reproduce the experiment in order to support the results, contributing to its maturity and its continuous improvement. In the end, we present a case study for an undergraduation course and discuss the results presenting a model for a digital ecosystem with web and mobile applications.
\end{abstract}

\section{Keywords}

Learning, Memorization, Information, Knowledge, Method

\section{Introduction}

Finding new ways to improve methods for leaning is always a worry and a subject for researches in many educational fields because the socials, economics and technological changes reflect how we retain information and transform them into knowledge, element that can transform the human being.

There is much information, and it is easily available, to everyone on the Internet, besides all the other traditional mass media like TV, Radio, Newspaper and so on. This scenario affects how teachers (professors or lecturers) handle knowledge, identify missed points in their students and help them link dots in the best way in spite of transmitting enough information to their students.

At this context, it seems non-viable to apply just one learning method to aim a goal, 
but it is necessary to use a group of methods and technics that help to learn in a complex world with non-linear information that we live today.

We believe that many areas can benefit from this present work as literacy, health and communication.

In literacy, the method can be applied for both off- and on-line courses to help the professor (instructor) to plan the content to be worked, selecting the essentials elements, as well as choose the way to give information. For example, for the students, or the learners, the aim is to motivate them to learn what they need to be approved on a test or a course.

In health and communication, the same principle can be applied with the difference of context. First, the method can help people with learning disabilities that have difficulties in remembering information, especially older adults or persons who carry some diseases (for instance, Alzheimer). The method can help to remember a sort of information in many fields: 1) in journalism-it can be helpful to alert people about some situations or to communicate utility facts, 2) in advertisement-it could help to memorize offers of products and services, and 3) to make public information about brands or companies.

This paper is an invitation to academic community, researchers and scientists to test the methods (presented in the next topic) in their fields to validate them.

This text is an adaptation from the mathematical representation of the methods for a universal understanding. The original study can be founded in Portuguese language at http://www.mapasdeconhecimento.com.br/.

In the end, we present a case study with the method application during the second semester of 2014 in a Web Design class at ESAMC Uberlândia Faculty.

This research did not receive any specific grant from funding agencies in the public, commercial, or not-for-profit sectors.

\section{Structured Knowledge Maps: About the Method}

It was mathematically demonstrated that a person can be considered a category (Barbosa Filho, 2013) and it turn possible to prepare a method based on Category Theory inspired by the Ausubel work and abstracting from Clusters and Functions Theory (Menezes \& Haueusler, 2001). In this way we can analyze objects as structured clusters and morphism as functions.

Figure 1 illustrates the function concept. The Function block is the function's name and, if necessary, its argument. At the Rule block is the process or the method to be executed.

The framework for Category Theory includes the Functor Theory that has its particularities like:

1) Category: actors involved in the process;

2) Objects: concepts to teach;

3) Morphism: methods or applications based on concepts;

4) Functor: elements for mapping between categories.

A functor represents the natural concept between categories, in other words, a func- 
tor can be considered like a homomorphism of categories. By homomorphism we can understand as an application (Functor) between two structures (Categories) so the constructor resulted (or its transformation) respect (or preserve) the structures' operations (Ginsburg, 1975).

Figure 2 presents the way that the elements from Functor Theory are related with each other. The first category is the sender. It represents which objects and morphism can be worked in some functor. The second category is the receiver. Its objects and morphism are in different color because it represents the way as the functor was learned by the receiver and are considered subcategories because its interpretations will never be exactly the same from the sender. It is important to verify on each step if these objects and morphism present on the receiver are valid before add a new knowledge.

The sender category can be a person or a machine, in others words, any communication actor with interest to transmit information or knowledge. The receiver category is usually a person, like a student, an apprentice, a patient or a product target.

Still in Figure 2, for instance, we can consider the sender category the teacher and the receiver category the student. The function is the knowledge about the right triangle from math. For teach this, the teacher needs to list the objects side, angle, legs (catheti), hypotenuse and altitude to teach the right triangle calculation, according to a determined method (morphism). It is important to verify how the student learned theses elements.

From the Functor Theory (Asperti \& Longo, 1991) we have to implement a functor between two categories and we must to accomplish the minimum requirement for that the objects and morphisms in the two categories are matched.

Thus the new knowledge (established by the functor) going to work concepts and

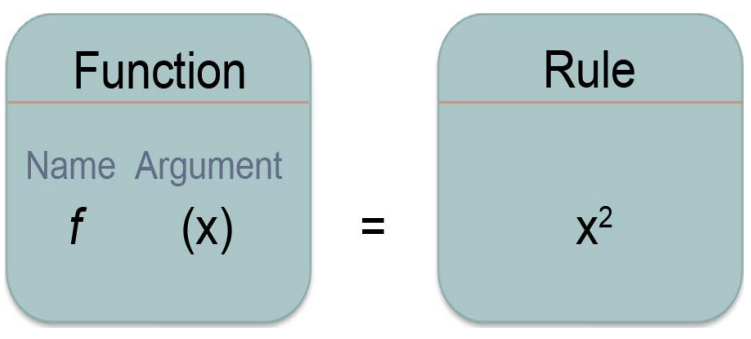

Figure 1. Function representation.

\section{Category 1}

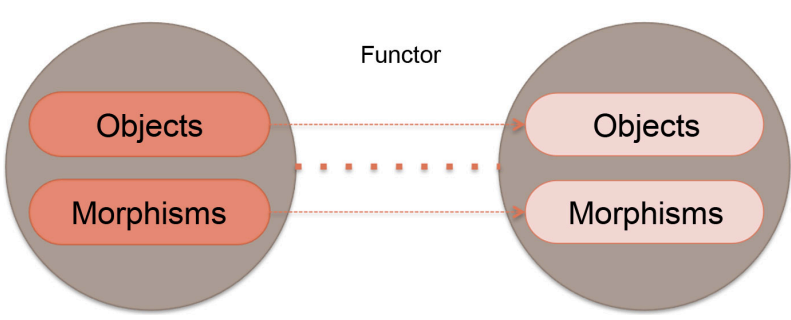

Figure 2. Categories, functor, objects, and morphism diagram. 
tools that the learner already owned (objects), as well as the proficiency uses of its basic tools (morphism). If the student/learner's category misses an object (by that mean a concept unknown) or morphism (how to manipulate the objects) the functor application (transmission of the new knowledge) fails (Barbosa Filho, 2013).

The aim of the function, on this context, is to warrant the knowledge transmission (learning) between the categories (professor and student). In this case, the ideal is the initial knowledge to be the most basic possible.

The knowledge transfer is only aimed when the student own a subcategory with objects and morphism set up by the professor, even in a minimum level, with a solid base for the functor establishment between the student and the professor and, thereafter, allowing the learning be updated.

According to Lima et al. (2013, 2014), relating functor with Structured Knowledge Maps means that it can create a progress knowledge radius to allow the student category be updated with the minimal objects and morphism required for the functor learning to be established. To move on with short radius and filling the ignorance area, the subclasses always be available to learn new knowledge, it means that could be possible to establish a functor that permits formally that the resulted action be possible.

The knowledge radius determines the content to be reached or transmitted and it needs that some concept had been learned before increase the radius and go to the next content to expand knowledge.

The dots to be learned are considered by us as ignorance dots that represent the missing knowledge or wrong concepts. It is necessary to make a research about the level of the existing information in the receiver category.

Is desirable to reach the full understanding about some kind of content to make the receiver category motivated to learn more and, for this method, the motivation is essential for learning.

In Figure 3 there is a circle where the radius (orange line) represents the knowledge to be transmitted and the ignorance area (green) provoked to the student. It is primordial that the first knowledge to be transmitted has the smaller radius possible to eliminate all the ignorance provoked. Some experiments (Barbosa Filho, 2013) presented that the satisfaction is proportional the missing ignorance and not the excess of knowledge. The less doubts in the receiver category the less ignorance will remain in the process teaching-learning about a specific topic and more motivated the person will be.

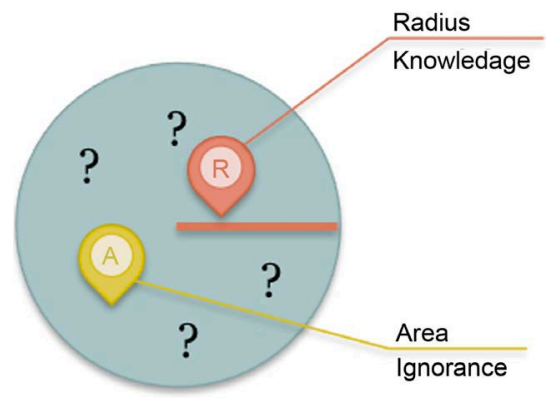

Figure 3. Structured knowledge map: first level. 
The use of the Structured Knowledge Maps (SKM) to help the students and the learners allow teachers to identify a small knowledge radius (dR) to after create with a minimal increase $(\mathrm{dA})$ in their ignorance area, as presented on Figure 4. With the ignorance eliminated it is possible track the content to be taught between professor and student.

Each interrogation point is an ignorance dot and it means that is an object or morphism to be worked. In the example given about the right triangle, the dots are: ?1 Angle; ?2 Side; ?3 Leg; ?4 Hypotenuse and ?5 Altitude in Figure 5 for Pythagorean Theorem, with its objects (ignorance's dots) to be worked.

From the smallest knowledge radius, in the next one it will be part of the start knowledge. The beginning is the foreknowledge and its ignorance area going to be transformed into acquired knowledge and indicated in the map (diagram) by an exclamation mark.

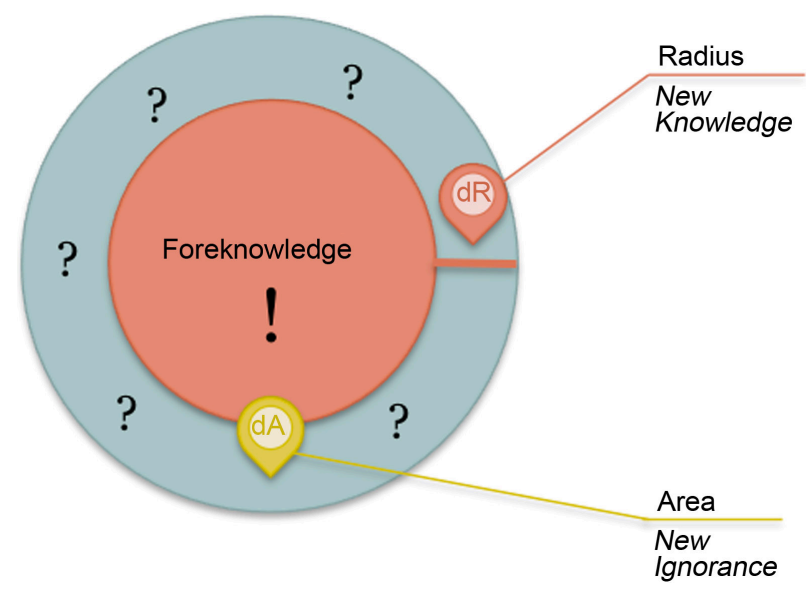

Figure 4. Structure knowledge map: second level.

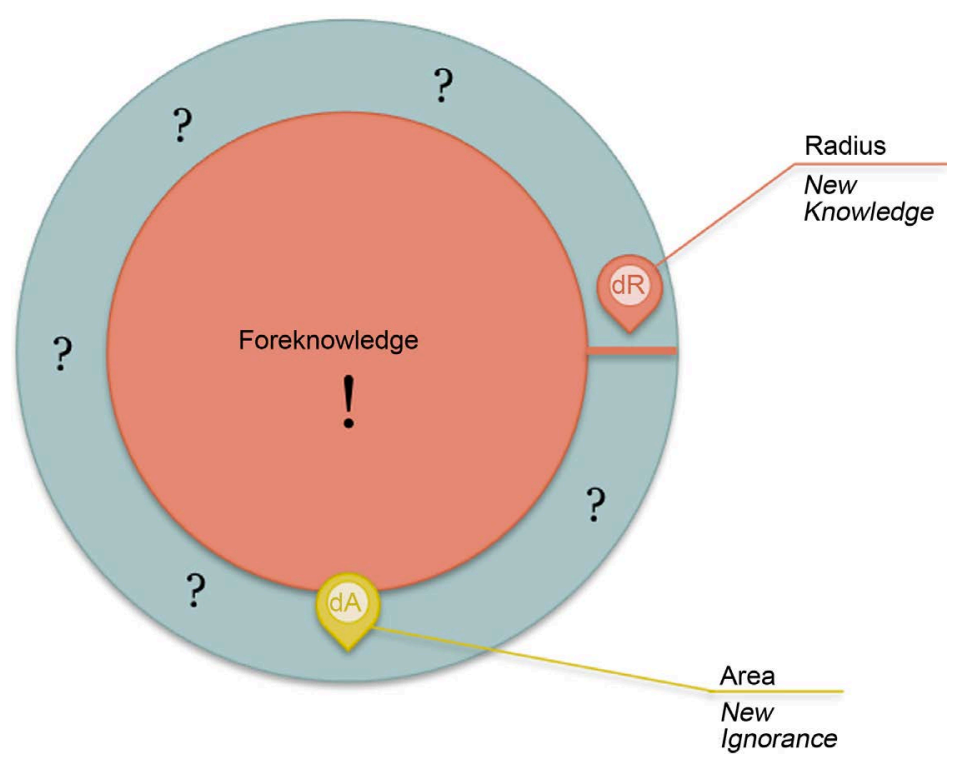

Figure 5. Structured knowledge map: third level. 
An ignorance area that wasn't eliminated causes displeasure to the learner and it can be the reason why students lose interest or give up of keep on going with the studies, sometimes can judge himself as incapable, even don't being. That is the reason why each module (new knowledge) must represent a controlled increment of the knowledge to be transmitted, as indicates in Figure 4 and Figure 5.

Doubts, wrong concepts and ignorance represent a barrier to the creation of a subcategory. Knowing theses elements is essential to filter them, eliminate them from the learner category and establish the functor aimed.

As said before, it is important for the knowledge transmission to demand from the learner category few objects and morphism. That way, for each functor (each new knowledge) must use the previous objects and morphism in the learner category, as shown in Figure 5.

There is possible to use the textual representation to detail each item. For example (Figure 6):

Must avoid overcharge objects and morphism because it can confuses the learner and makes him put others (objects and morphism) that don't belong to the context or the subcategory. It can cause in the learner an attempt to attach the wrong objects and morphism to the new knowledge. The excess of objects and morphism is undesirable as much as the absence.

In situations that needs the knowledge transmission or manage information in a constant way to achieve a goal at the end a long period of time, for instance, after six month or a year course, it is important to adopt another method to help memorize the content learned to avoid missing it and convert it again to ignorance dots that impairs

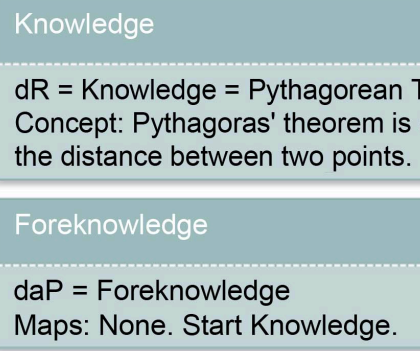

References

IEZZI, Gelson. Fundamentals of Elementary Mathematics 3: trigonometry. $5^{\text {th }}$ ed. São Paulo: Atual,1983.

Figure 6. Textual format as alternative for presents the knowledge radius and the ignorance areas. 
some content module.

For that reason, we present a conceptual review in a based-2 interval time $\left(2^{n}\right)$ in days to make possible that what was learned keeps memorized by the student (receiver category) while he don't have any problem or disease that damage the brain. We believe that by using this method the memorization can be long end effective.

For this complementation method, the content must be reviewed in a time interval as suggested in Figure 7. It doesn't need to go back to the concept, just apply it in the context, at the specific moment. It was named Based-2 Effective Exponential Memorization Method (B2EEMM) because it uses a Learning Reinforcement Interval (LRI), a based-2 system $\left(2^{\mathrm{n}}\right)$.

Using the Knowledge Maps with the Based-2 Method of Memorization allows the practice of teaching or even another activity that needs to retain information more effectively. The combination of these two methods is illustrated in Figure 8.

Days interval

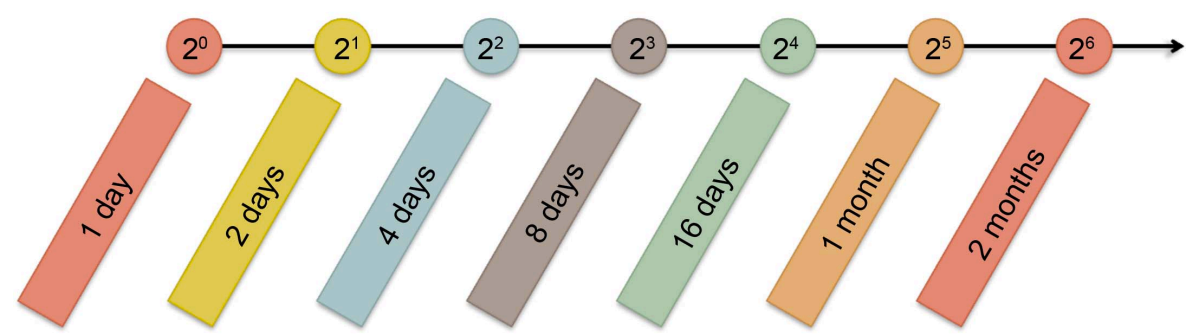

Figure 7. Based-2 Effective Exponential Memorization Method (B2EEMM).

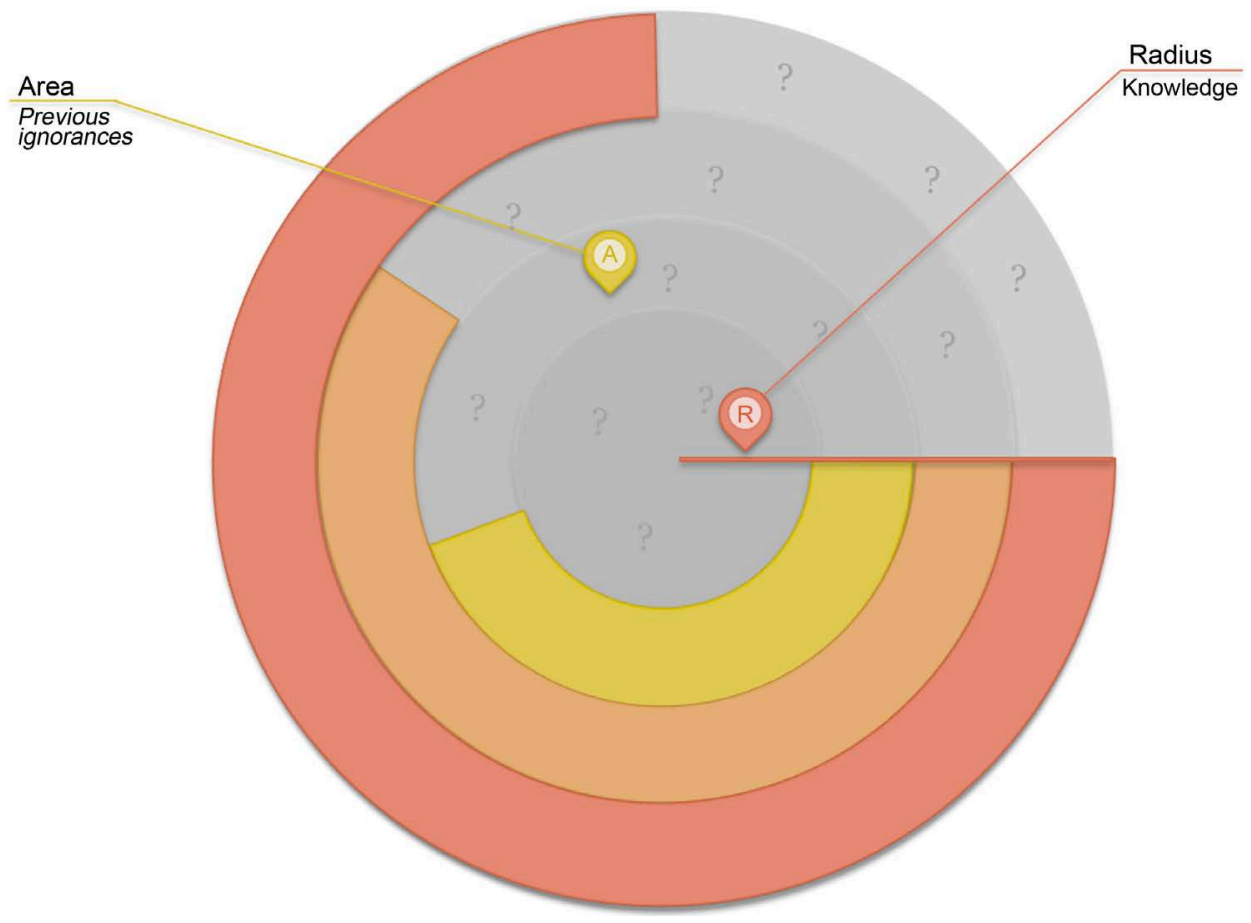

Figure 8. Spiral of knowledge. 
In the Figure above presents each time that the knowledge had been applied and the concepts redeemed in the learning process. That way, the professor (sender category) and the student (receiver category) have more control of what must to be learn and what effectively as learned, engaging the learning process through the motivation.

\section{Transitivity Compounded of Functors}

The Structured Knowledge Maps is also possible to coach a group leader and train him to teach another person. In this case, the knowledge sender (professor, instructor or coach) maps the objects and morphism to the intermediate category that represents the group leader. He also maps the objects and morphism to the receiver category (student or learner).

The knowledge transmission from intermediate category to the receiver category is equivalent to say that the mapping was linked from the sender category direct to the receiver category without the intermediate category.

Figure 9 illustrated this scenario:

The intermediate category can be a person or an intelligent system. The latter could be a persona from trendsetters on a digital environment like social media with many followers.

\section{Case Study: Methods Tested in an Undergraduation Discipline}

The both methods Knowledge Maps and 2n Memorization were adopted to help students from 19 to 27 years old in a communication courses at the ESAMC Uberlândia Faculty to learn the content of Web Design.

This discipline represents, on the students' perception, a deviance on the content for their course but it is important to show up to them the meaning of this studies and engage participation because it is necessary to learn HTML and CSS (scripting language) at computer lab. We used the Structured Knowledge Maps to plan each class and track the evolution of the group.

In this experiment, a survey was applied in the first class to identify deviances about the foreknowledge about the content. In a group with 31 people only four had some basic knowledge about the theme.

\section{Category 1}

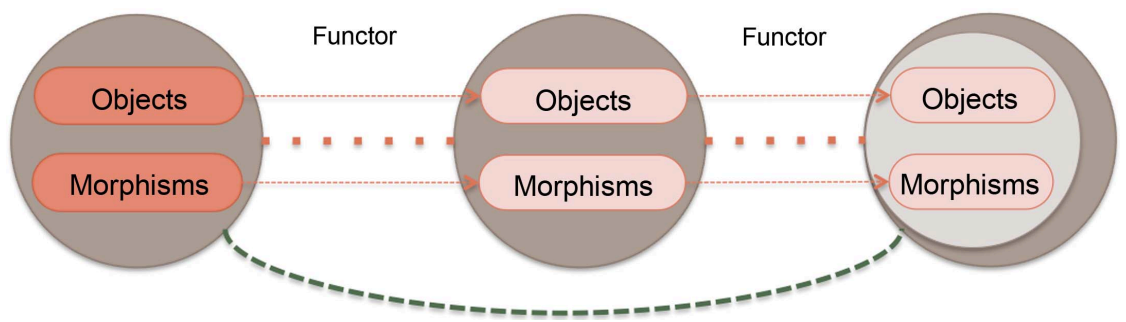

Figure 9. Transitivity compounded of functors. 
This study was supervised by the method's mentor in a postgraduation program in Artificial Intelligence at Universidade Federal de Uberlândia (UFU). The researchers published some of their notes from their journal of field on the research group's blog available on www.mapasdeconhecimento.com.br (Portuguese language).

The final survey had a sample of 20 people from the 31 people in the research universe and it was applied at the end of 2014.

The experiment was monitored for four month and we worked six functors: 1) hypertext; 2) languages; 3) design versus development; 4) digital convergence; 5) HTML and CSS editors; and 6) interface design.

We didn't list the objects and morphism for each functor because it could overextend the text and some notes about the lesson planning can be accessed on the blog. The aim is the results under the professor's point of view.

Before the beginning of the semester, the discipline's content was analyzed by Structured Knowledge Maps perspective. For each topic we analyzed the knowledge to be transmitted (functor) and which elements were necessaries to these transmission is effective (objects and morphism).

Two surveys were applied, the first was in the classroom and the last was on line through the Moodle platform.

With the first one we aimed to identify the technical knowledge level about the discipline's content and the individual skills. The second one, our goal was to measure the class evolution.

The Structured Knowledge Maps helped to rethink the amount of information that the students are exposed that could cause a decrease the interest about the content losing the motivation to learn. According the methodological approach, the motivation is essential aspect of learning.

The aimed engagement could be perceived in the second module when HTML and CSS languages were taught and it represents the practice at the computer lab. In the first module, we worked the Hypertext and Languages functor. The students thought they were only an introduction and ignored them. Even after remind them about some concepts and applications. The initial hypotheses were that the content was more philosophical about cyberspace and cyber culture.

The meeting was weekly and it was inappropriate use the $2 n$ Memorization Method only in the classroom. For this reason, we adopted the Moodle platform to follow closer as a blended environment of learning. All the students signed on and tasks with badges were used engaging many of them. But it wasn't enough to overpass the technological barrier for few people that decreased the interest for some of them, including a trendsetter that gave up and influenced colleagues to do the same. The group started with 31 students and finished with 24 students.

At the end of September, we created an email-based group on Google Groups. After that the student interest returned because everyone got access to the information because we used a digital tool that they already know: email.

One week before the end of the semester, the last survey was applied with a structure 
form including Likert scale to identify the students' perception about the discipline and the professor.

After the experience, the need was evident to think tools that allow the methods applications in its full requirement to help the professor to track the evolution of their students and allow intervening before the students gave up.

\subsection{Survey}

The form was applied in the classroom with a sample of 20 students, age from 19 to 27 years old and most of them female (60\%).

The main goals were to identify the student perception about the content, the tools efficiency and verify if the profession position was adequate.

Our secondary goals were:

Verify if the student perceive the Web Design discipline important.

Identify the understanding level about the content application in practice.

Contrast the recognition level about the discipline's topics.

Recognize the tools efficiency.

Investigate the methods efficiency.

Question if the professor's attitudes were consistent with the teaching and learning approach.

Generally, we believe that the kind of content being very different from others disciplines in the course may cause resistance and requires more effort to learn.

To reach the goals, the survey form had four sections: profile, discipline content, tools and techniques, and about the professor.

In the profile section there were three questions: course, age, and gender. In the others sections there were six questions within in each one totalizing 21 items in the survey form.

The charts present the data for to the three last sections mentioned above. The Likert scale with five response categories to represent an interval-level of measurement (Hill \& Hill, 2009), the number five (5) represents the extreme positive (strongly agree) and the number one (1) the extreme negative (strongly disagree). Below the weighted averages can be visualized.

\subsection{Results and Discussion}

About the discipline's content (Figure 10), the students starts to know the importance of web design in a communication context (Q1), although some of them still have difficulty to relate the subject on their professionals fields (Q2 to Q5), with a highlight to HTML and CSS (Q4) - topic which had more engagement. Due to experiences in the previous semesters, we adopted the learning tool on CodeAcademy.com to help students study HTML and CSS at home and it was evident that this tool was effective (Figure 11, Q8) for the students. Another efficient tool adopted was the discussion group on Google Groups. However the Moodle and the Blog was not sufficient to engage them to help with the learning process. 
The average for each section was: 1) Discipline's content 3.84; 2) Methods and Tools 3.56; and 3) about the professor 4.21.

It seems that the professor (Figure 12) wasn't the element that caused demotivation Content of Web Design

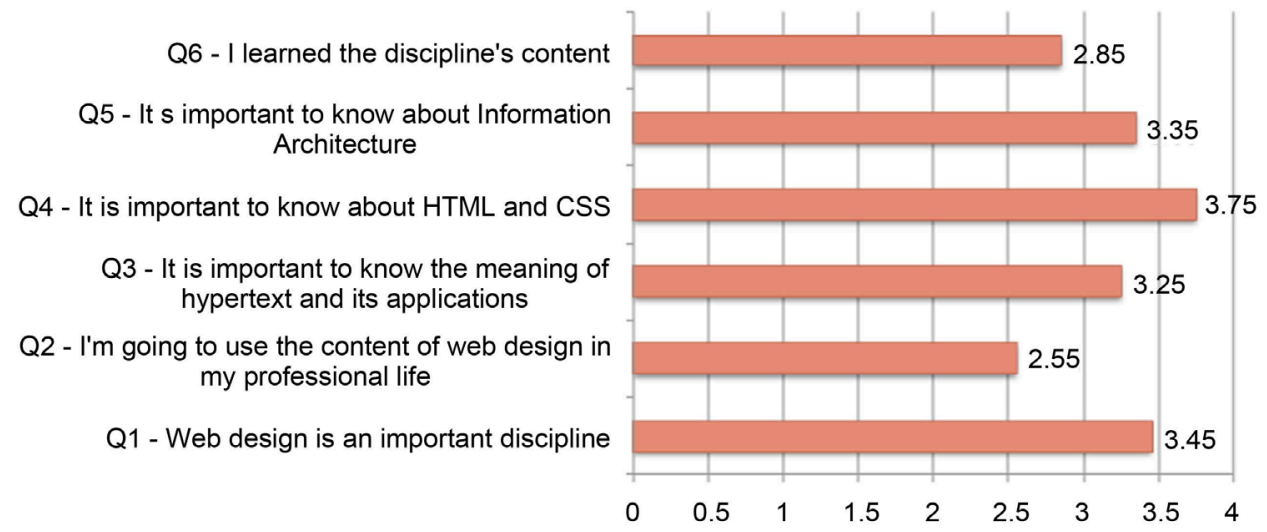

Figure 10. About the content of web design.

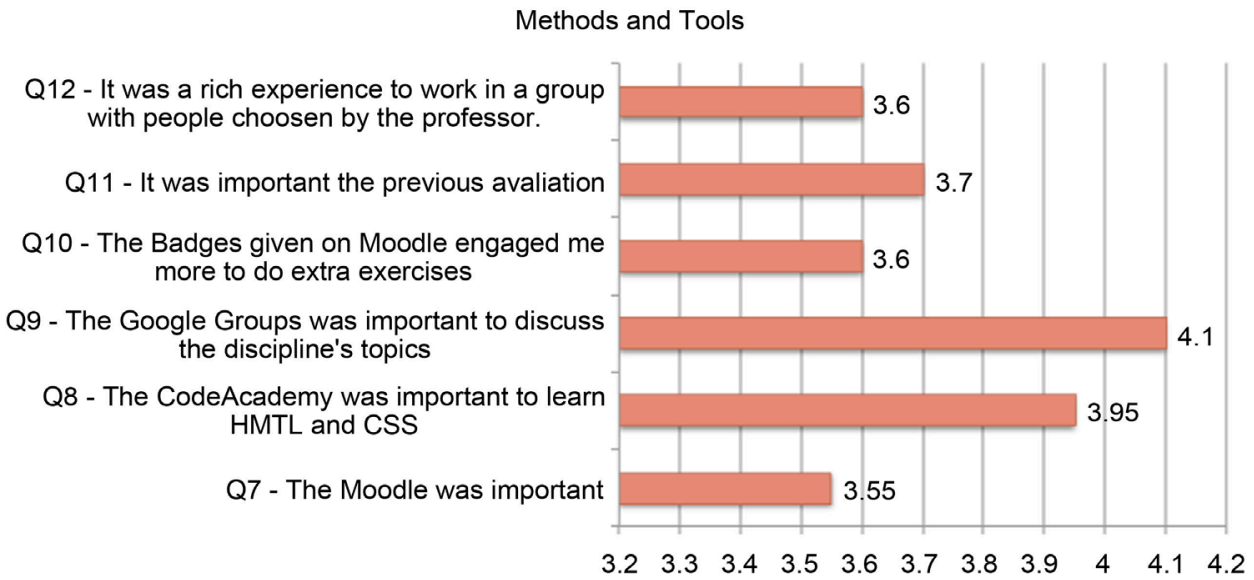

Figure 11. About the methods and tools adopted in the discipline.

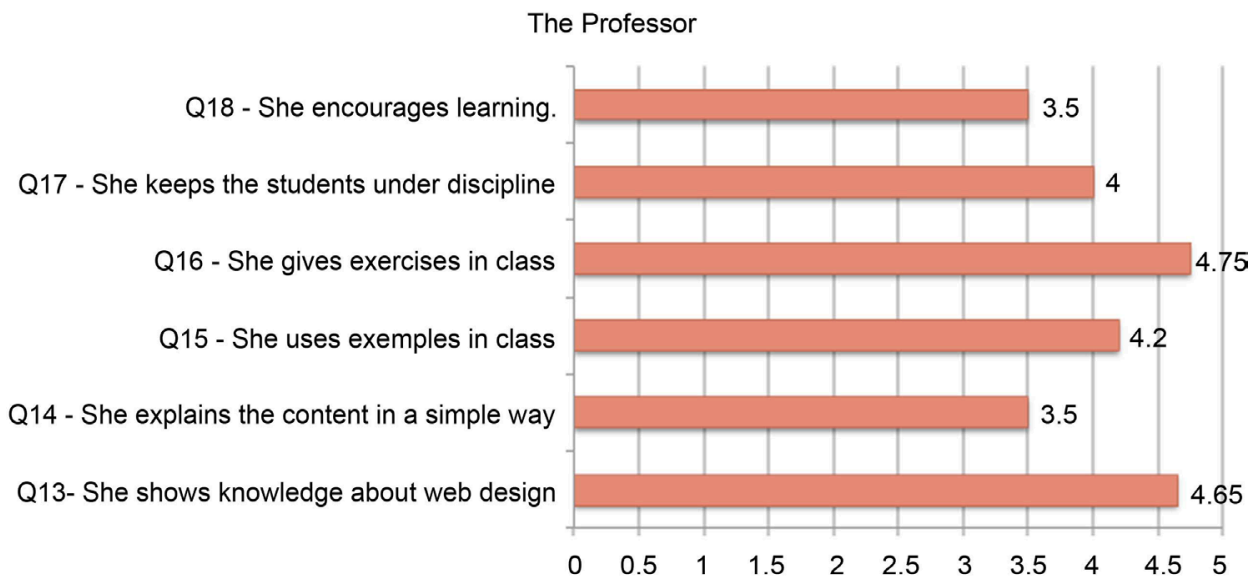

Figure 12. About the professor. 
but it was difficult to understand the discipline's content, proving hypothesis during the experiment.

In this study was possible to check the efficiency of the methods presented. We suggest a software development to support the professor and the student for they both achieve their goals and help them to follow the content's evolution in the discipline and shows the students difficulties more clearly to help them before the demotivation occurs to the point to compromise the learning process.

Based on this case study, it allowed to us modeling the software process with a two users interfaces (Bizagi, 2016), one for the student and another for the professor. The process modeling can be seen in Figure 13.

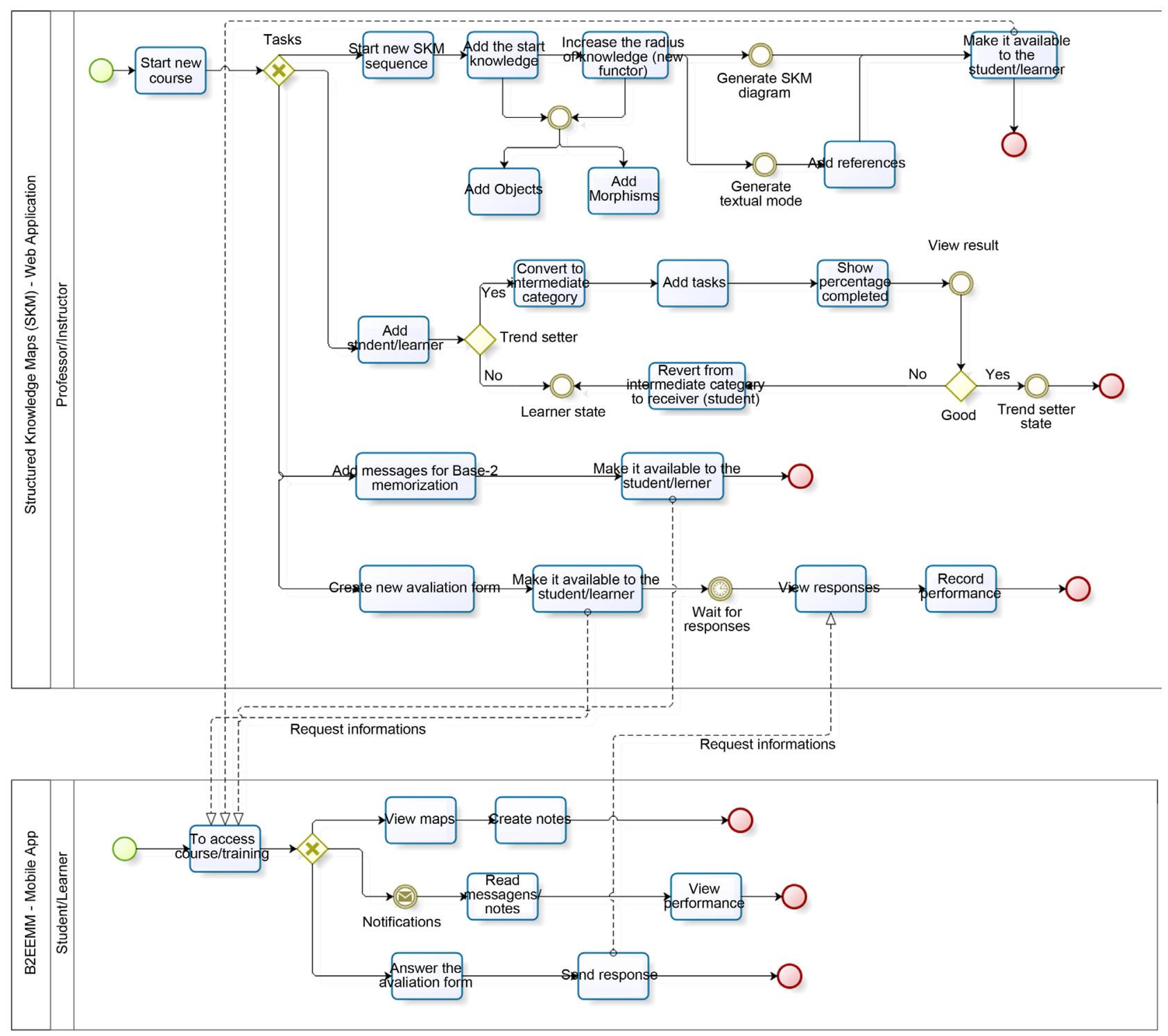

Figure 13. Software process model. 
These procedures of data input will allow the professor/instructor to follow each student/learner to allow the adaptive learning occurs because without the right tools it was difficult and hardworking to the professor controls all the activities, besides it consume a lot of time in the classroom that must be dedicated to explanations, examples and practical activities.

A software developed to apply these methods could work with the intermediate category and by that means to identify the student that is a trendsetter to help the others students learn based their own reality using an adaptive language helping them to understand complex subjects.

The diagram in Figure 13 presents the activities that both professor/instructor (web application) and the student/learner (mobile application) can do on the system and their connections.

\section{Conclusions}

The Structured Knowledge Maps (SKM) and Based-2 Effective Exponential Memorization Method (B2EEMM) have their potential uses in many fields that need to send information and retain knowledge.

Some of them could be in 1) education, between student and professor, contributing with the learning process, 2) communication, between the media and its target, to keep information, and 3) health, between nursing and patient, to rescue the citizenship.

Although many methods are available for reaching these goals, it is still possible to combine the suggested approach with others. The only thing that differentiates them to the others is its contemporaneity because we live in a world surrounded by non-linear information and the methods based on the new technologies help us to keep the information organized and memorize what is useful.

To support the academic community, some materials about these methods are available in Portuguese language on http://www.mapasdeconhecimento.com.br/.

\section{References}

Asperti, A., \& Longo, G. (1991). Categories Types and Structures: An Introduction to Category Theory for the Working Computer Scientist, Foundations of Computing Series. Massachusetts: MIT Press.

Barbosa Filho, R. (2013). An Approach to Teaching Based on the Theory of Meaningful Learning Using the Theory of Categories. $\mathrm{PhD}$ Thesis. Uberlândia: Universidade Federal de Uberlândia, $110 \mathrm{p}$. http://coronasdkgames.com/mapas2n/wp-content/uploads/2014/05/Tese-Barbosa-Filho.pdf

Bizagi (2016). BPMN Software for Process Modeling (Community Edition). Version 3.0. http://www.bizagi.com/en/products/bpm-suite/modeler)

Ginsburg, S. (1975). Algebraic and Automata Theoretic Properties of Formal Languages. Amsterdam: North-Holland.

Hill, M. M., \& Hill, A. (2009). Research by Questionnaire (2nd ed.). Sílabo: Lisboa.

Lima, L. V., Ferreira, D. C. M., Camargo Júnior, H., \& Schiovato, N. S. C. (2014). Structured Knowledge Maps: New Methodological Approach for Teaching and Learning. Educere et 
Educare, 9. http://e-revista.unioeste.br/index.php/educereeteducare/article/view/10122

Lima, S. F. de O., Barbosa Filho, R., Lima, L. V., \& Camargo Júnior, H. (2013). Knowledge Maps: A Learning Tool via Information Cards as a Teaching Tool. Unopar Journal, 14, \#1.

Menezes, P., \& Hausier, E. (2001). Category Theory to Computer Science. Porto Alegre: EditoraSagra Luzzato.

Submit or recommend next manuscript to SCIRP and we will provide best service for you:

Accepting pre-submission inquiries through Email, Facebook, LinkedIn, Twitter, etc. A wide selection of journals (inclusive of 9 subjects, more than 200 journals)

Providing 24-hour high-quality service

User-friendly online submission system

Fair and swift peer-review system

Efficient typesetting and proofreading procedure

Display of the result of downloads and visits, as well as the number of cited articles

Maximum dissemination of your research work

Submit your manuscript at: http://papersubmission.scirp.org/

Or contact ce@scirp.org 